\title{
A novel biomimetic nanomedicine system with anti-inflammatory and anti-osteoporosis effects improves the therapy efficacy of steroid-resistant nephrotic syndrome
}

\author{
Jian Li ${ }^{1}$, Mingyi Zhao ${ }^{2}$, Xinying Xiang ${ }^{3}$, Qingnan $\mathrm{He}^{2^{*}}$ and Rong Gui ${ }^{*^{*}}$ (1)
}

\begin{abstract}
Clinically, steroid-resistant nephrotic syndrome (SRNS) is always prolonged and difficult to treat and easily develops into end-stage renal disease, resulting in a low survival rate. Strategies to reverse steroid resistance and reduce the long-term use of high doses of steroid medicines are urgently needed. In this study, a novel nanoparticle drug system (Pm-GCH) with a core-shell structure was designed. Metal-organic frameworks, synthesized by glycyrrhizic acid $(\mathrm{G})$ and calcium ions $\left(\mathrm{Ca}^{2+}\right)$ loaded with hydrocortisone $(\mathrm{H})$ were the core of the nanoparticles. Platelet membrane vesicles were the shells. The natural platelet membrane endows Pm-GCH with good biocompatibility and the ability to promote immune escape. In addition, under the chemotaxis of inflammatory factors, platelet membranes assist Pm-GCH in nonspecific targeting of the inflammatory sites of the kidney. Under an inflammatory acid environment, GCH slowly degrades and releases glycyrrhizic acid and hydrocortisone. Glycyrrhizic acid inhibits the inactivation of hydrocortisone, jointly inhibits the activity of phospholipase A2 (PLA2) and the classic activation pathway of complement C2, blocks the production of inflammatory factors, plays an anti-inflammatory role, and enhances the efficacy of hydrocortisone in the treatment of SRNS. Moreover, glycyrrhizic acid alleviates osteoporosis induced by long-term use of glucocorticoids. These results indicate that Pm-GCH is a promising treatment strategy for SRNS.
\end{abstract}

Keywords: Steroid-resistant nephrotic syndrome, Biomimetic, Glycyrrhizic acid, Inflammatory

\footnotetext{
*Correspondence: heqn2629@csu.edu.cn; guirong@csu.edu.cn

${ }^{1}$ Department of Blood Transfusion, The Third Xiangya Hospital, Central

South University, Changsha 410013, China

2 Department of Pediatrics, The Third Xiangya Hospital, Central South

University, Changsha 410013, China

Full list of author information is available at the end of the article
}

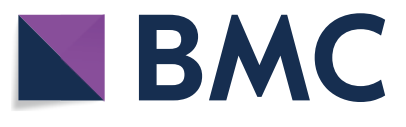
permits use, sharing, adaptation, distribution and reproduction in any medium or format, as long as you give appropriate credit to the original author(s) and the source, provide a link to the Creative Commons licence, and indicate if changes were made. The images or other third party material in this article are included in the article's Creative Commons licence, unless indicated otherwise in a credit line to the material. If material is not included in the article's Creative Commons licence and your intended use is not permitted by statutory regulation or exceeds the permitted use, you will need to obtain permission directly from the copyright holder. To view a copy of this licence, visit http://creativecommons.org/licenses/by/4.0/. The Creative Commons Public Domain Dedication waiver (http://creativeco mmons.org/publicdomain/zero/1.0/) applies to the data made available in this article, unless otherwise stated in a credit line to the data. 


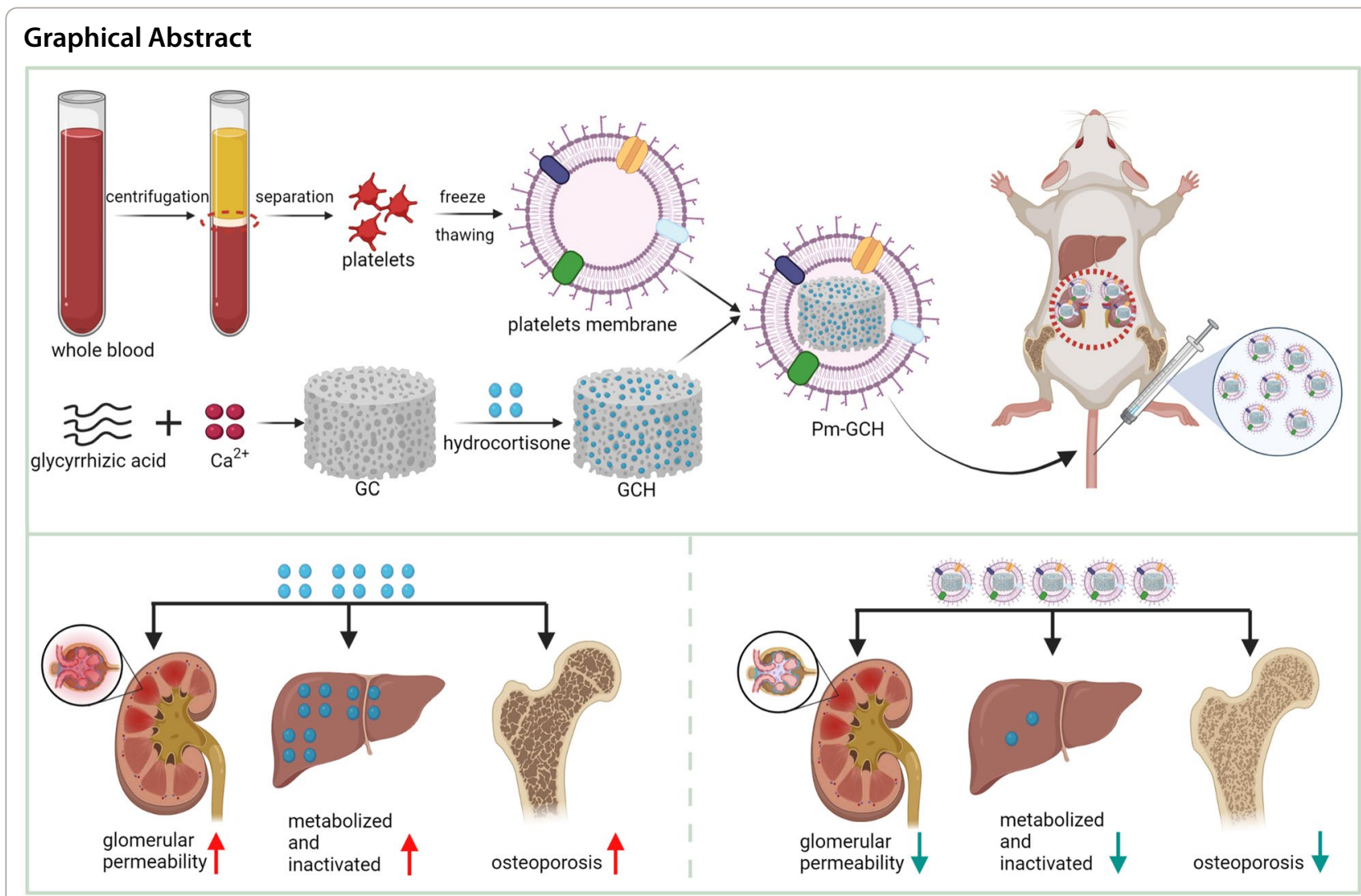

\section{Introduction}

Primary nephrotic syndrome (PNS) is a clinical syndrome characterized by increased permeability of the glomerular filtration membrane and loss of a large amount of plasma protein from the blood, resulting in a high level of proteinuria, hypoproteinemia, hyperlipidemia and varying degrees of edema [1]. Most patients with PNS are sensitive to glucocorticoids, but $10-20 \%$ of patients do not have relieved proteinuria after 8 weeks of treatment with a sufficient amount of hormones, and thus develop steroid-resistant nephrotic syndrome (SRNS) [2]. The incidence of osteoporosis is up to $30 \%$ after long-term (over 6 months) use of high-dose glucocorticoids, and the incidence of glucocorticoid-induced osteoporosis (GIOP) ranks third in osteoporosis [3, 4]. Therefore, effective prevention and treatment of GIOP is very important in the treatment of SRNS. SRNS is a common disease caused by multiple factors. As a highrisk factor for nephrotic syndrome events, SRNS can induce renal tubulointerstitial fibrosis, which easily develops into end-stage renal disease and endangers the lives of patients [5, 6].

In vivo, glucocorticoids were mostly metabolized and inactivated by the liver microsomal cytochrome
P450 enzyme system, resulting in low bioavailability. For example, hydrocortisone can be metabolized by P4503a (CYP3A) to 6 $\beta$-hydroxy hydrocortisone, which is easily excreted from urine [7,8]. Glycyrrhizic acid is a saponin component extracted from the traditional Chinese medicine licorice $[9,10]$. Glycyrrhizic acid has anti-inflammatory, immunomodulatory, anticoagulant and steroid-like effects and is widely used in clinical practice [11, 12]. Studies have found that glycyrrhizic acid has an inhibitory effect on P450 enzymes, so it can be inferred that glycyrrhizic acid combined with hydrocortisone can reduce the inactivation of glucocorticoids in the liver and enhance its bioavailability [13]. Moreover, glycyrrhizic acid has steroid-like effects, and can be hydrolyzed to glycyrrhetinic acid, whose chemical structure is similar to that of steroid hormones, in vivo [14]. Glycyrrhetinic acid can bind to glucocorticoid receptors and has a weak glucocorticoid-like effect [15]. In addition, glycyrrhizic acid can block the production of inflammatory mediators by inhibiting the activity of phospholipase A2 and the classical activation pathway of complement $\mathrm{C} 2$, thus exerting anti-inflammatory effects [16, 17]. Glycyrrhizic acid has the structural 
characteristics of saponin amphiphilic substances and can interact with cholesterol or phospholipids on cell membrane to induce porosity and enhance membrane permeability. As a result, glycyrrhizic acid can freely pass through the membrane $[18,19]$. Moreover, glycyrrhizic acid was shown to inhibit the differentiation of osteoclasts by regulating the NF- $\mathrm{kB}$ pathway, increase the mineral content of the femur, and have a protective effect on glucocorticoid-induced osteoporosis [20].

As a powerful driver in biomedical development, nanotechnology has shown great promise in the fields of early diagnosis, treatment, prevention of disease and bioengineering [21-23]. Nanomaterials loaded with traditional drugs can reduce the dosage of drugs and lead to targeted slow release [24]. Moreover, a multifunctional drug carrier system can be designed to achieve synergistic therapeutic effects [25]. Metal-organic frameworks (MOFs) are bridged by metal ions and organic ligands, which have a high specific surface area and porosity, have multiple ligand sites and show easy chemical modification $[26,27]$. In this study, a porous metal-organic framework (GC) was prepared using glycyrrhizic acid and calcium ions $\left(\mathrm{Ca}^{2+}\right)$.

Nanomaterials, as exogenous substances in the body, are easily eliminated [28]. To solve this problem, this study intends to use a natural platelet membrane to camouflage nanoparticles $[29,30]$. The self-recognition molecule CD47 on the platelet membrane surface results in a prolonged cyclic half-life, enhanced immune escape, and incomparable biocompatibility of the core nanoparticles [31, 32]. In nephrotic syndrome, inflammation occurs in the kidney. Under the action of inflammatory factors, platelet membrane aggregates at the inflammatory site and plays a targeted role [33]. Furthermore, some studies have found that in the case of nephrotic syndrome, the abnormally activated platelets in the body aggregate at the inflammatory site, degranulate, release inflammatory factors and aggravate inflammation at the lesion site [34, 35]. Therefore, in this study, in addition to the targeting effect of platelet membrane vesicles, they could also compete with platelets in vivo to bind to inflammatory sites, reduce platelet activation and weaken the inflammatory response.

In this study, a metal-organic framework was constructed by glycyrrhizic acid and calcium ions with hydrocortisone $(\mathrm{H})$ as the core, and a platelet membrane was used as the shell structure of the nanodrug system (Pm-GCH). Through platelet membrane camouflage, Pm-GCH not only nonspecifically targets the inflammatory site of nephrotic syndrome but can also compete with the inflammatory site and weaken the inflammatory response. In addition to a raw material for carrier synthesis, glycyrrhizic acid also has anti-inflammatory and inhibitory effects on glucocorticoid inactivation and anti-osteoporotic effects. Pm-GCH has a synergistic effect in the treatment of steroid-resistant nephrotic syndrome and provides a new therapeutic strategy for nephropathy.

\section{Materials and methods Materials}

Glycyrrhizic acid (DG0006) was manufactured by Chengdu Desite Biological Technology Co., Ltd (Chengdu, China). Hydrocortisone (A610506) and calcium chloride (A501330) were purchased from Sangon Biotech Co., Ltd. (Shanghai, China). DMEM (11965092), RPMI 1640 (11875119), fetal bovine serum (10270106), penicillin streptomycin (15140122, $5000 \mathrm{U} / \mathrm{ml})$, and trypsin (25200056) were purchased from Gibco (Thermo Fisher Scientific, USA). Serum-Free Cell Freezing Medium (C40100) was produced by New Cell \& Molecular Biotech Co., Ltd. (Suzhou, China). The Calcein/PI Cell Viability/Cytotoxicity Assay Kit (C2015M) was produced by Beyotime Biotechnology (Shanghai, China). Millex Syringe Filters $(400 \mathrm{~nm}$ and $200 \mathrm{~nm}$ ) were purchased from Millipore (USA). The dialysis membrane (MW 1000D, YA1047) and hematoxylin-eosin Contamination Kit were purchased from SolarBio Science \& Technology Co., Ltd. (Beijing, China). Anti-phosphoolipase A2 (ab239730) and Anti-component 2 (ab231651) monoclonal antibodies were manufactured by Abcam (USA). FITC-conjugated goat anti-mouse IgG (BA1101) and CY3-conjugated goat anti-rabbit IgG (BA1032) were obtained from Boster Biological Technology Co., Ltd. (Wuhan, China).

\section{Preparation of Pm-GCH Preparation of platelet membrane vesicles (Pm)}

As mentioned above, fresh mouse whole blood was placed in a sodium citrate anticoagulant centrifuge tube and centrifuged at $1000 \mathrm{rpm}$ for $10 \mathrm{~min}$, and the supernatant was collected to obtain platelet-rich plasma. Due to the presence of a certain amount of RBCs in the obtained platelet-rich plasma, $1 \%$ ammonium oxalate was added to lyse RBCs. After centrifugation at $3500 \mathrm{rpm}$ for $15 \mathrm{~min}$, the supernatant was discarded, and platelets were precipitated. Platelets were resuspended in normal saline, placed in a $-80{ }^{\circ} \mathrm{C}$ refrigerator for repeated freeze-thawing to release the platelets contents, and centrifuged at $5000 \mathrm{rpm}$ for $15 \mathrm{~min}$. The supernatant was discarded, and the membrane precipitate was washed repeatedly with PBS for 3 times and resuspended in water. Ultrasound $(42 \mathrm{kHz}, 100 \mathrm{~W})$ was performed for $10 \mathrm{~min}$. The particle size of Pm was detected by dynamic light scattering (DLS). 


\section{Construction of $\mathrm{GCH}$}

Glycyrrhitic acid $(0.8 \mathrm{~g})$ and calcium chloride $\left(\mathrm{CaCl}_{2}\right.$, $0.1 \mathrm{~g})$ were dissolved in $10 \mathrm{ml}$ double distilled water, respectively. Glycyrrhitic acid was added dropwise to the $\mathrm{CaCl}_{2}$ solution and magnetically stirred until the solution turned milky-white to form GC. The solution was then centrifuged and washed with double distilled water 3 times, and the powder was lyophilized in a vacuum freeze dryer for later use. The morphological characteristics of GC were monitored by transmission electron microscopy (TEM) and scanning electron microscopy (SEM). PBS ( $2 \mathrm{ml})$ was used to dissolve GC $(4 \mathrm{mg})$, and anhydrous ethanol $(2 \mathrm{ml})$ was used to dissolve hydrocortisone $(1.6 \mathrm{mg})$. GC and hydrocortisone $(\mathrm{H})$ were mixed dropwise and stirred for $24 \mathrm{~h}$, and then added to a dialysis bag to remove the unbound hydrocortisone to obtain $\mathrm{GCH}$. The optical density (OD) of the dialysate at $235 \mathrm{~nm}$ was determined. The content, encapsulation efficiency (EE) and loading efficiency (LE) of hydrocortisone in the dialysate were calculated according to the following formula:

$$
\begin{aligned}
\mathrm{EE}= & \text { mass of } \mathrm{H} \text { into nanoparticles } \\
& / \text { mass of the feeding } \mathrm{H} \times 100 \% \\
\mathrm{LC}= & \text { mass of } \mathrm{H} \text { into nanoparticles } \\
& /(\text { mass of } \mathrm{GCs}+\text { mass of } \mathrm{H} \text { into nanoparticles }) \times 100 \%
\end{aligned}
$$

\section{The fusion of GCH and Pm}

A constant volume $(0.5 \mathrm{ml})$ of $\mathrm{Pm}(1.25 \mathrm{mg} / \mathrm{ml})$ and $\mathrm{GCH}$ suspension (hydrocortisone level $(\mathrm{H}), 1 \mathrm{mg} / \mathrm{ml}$ ) were mixed and then ultrasonicated in a water bath $(30 \mathrm{~min}$, $42 \mathrm{kHz}, 200 \mathrm{~W}$ ), followed by extraction through a $200 \mathrm{~nm}$ pore needle filter. After centrifugation at $5000 \mathrm{rpm}$ for $15 \mathrm{~min}$, the excess Pm in the supernatant was discarded, and the precipitate obtained was $\mathrm{Pm}-\mathrm{GCH}$.

\section{Characterization of Pm-GCH}

Zetasizer Nano (Malvern, UK) was used to detect the hydrodynamic size and zeta potential of Pm-GCH. TEM (HT7800, HITACHI, Japan) was used to detect the size and morphology of Pm-GCH. The UV-Vis absorption of $\mathrm{GC}(0.25 \mathrm{mg} / \mathrm{ml}), \mathrm{H}(1 \mathrm{mg} / \mathrm{ml}), \mathrm{Pm}(2 \mathrm{mg} / \mathrm{ml})$ and Pm$\mathrm{GCH}(1.5 \mathrm{mg} / \mathrm{ml})$ was detected by a UV-Vis spectrometer (2600, Shimadzu, Japan). The platelet membrane protein composition was determined by SDS-PAGE. Then, Comassie Blue staining solution (P1305, SolarBio, China) was used to stain the gel. After decolorization, the gel imaging system was used for analysis.
Release characteristics of glycyrrhizic acid and hydrocortisone in $\mathrm{Pm}-\mathrm{GCH}$ in vitro

One milliliter of Pm-GCH was added to three dialysis bags and placed in PBS buffers at $\mathrm{pH}=6.5$ and $\mathrm{pH}=7.4$. Dialysate was taken at $2 \mathrm{~h}, 6 \mathrm{~h}, 12 \mathrm{~h}, 24 \mathrm{~h}, 48 \mathrm{~h}$, and $72 \mathrm{~h}$, and its absorbance at $235 \mathrm{~nm}$ (hydrocortisone characteristic absorption peak) and $252 \mathrm{~nm}$ (glycyrrhizic acid characteristic absorption peak) was detected. The absorbances of hydrocortisone and glycyrrhizic acid with different concentration gradients at $235 \mathrm{~nm}$ and $252 \mathrm{~nm}$ were determined, and the standard curves were established. The hydrocortisone and glycyrrhizic acid contents in the dialysate and drug release curve were calculated.

\section{Biocompatibility assessment in vitro}

First, the blood compatibility of Pm-GCH was detected by a hemolysis test. Rabbit red blood cells (5\%) were incubated with different concentrations of $\mathrm{GCH}$ and $\mathrm{Pm}-\mathrm{GCH}$ in a water bath at $37{ }^{\circ} \mathrm{C}$ for $2 \mathrm{~h}$. After centrifugation (1500 rpm, $10 \mathrm{~min}$ ), the supernatant was collected, and its absorbance at $545 \mathrm{~nm}$ was measured using a UV-Vis spectrophotometer (Enspire 2300, PerkinElmer, USA). The immune evasive ability of Pm-GCH was assessed in a murine peritoneal macrophages (MPMs) uptake assay. The MPMs were incubated with Cy5-labeled $\mathrm{GCH}$ and Pm-GCH for $30 \mathrm{~min}$ and photographed under an inverted laser microscope (Zen2, Zeiss, Germany). Cell lysates were added to lyse the cells. The lysates were centrifuged and the supernatant was extracted. The fluorescence intensity at $664 \mathrm{~nm}$ was detected by a microplate detector (Enspire 2300, PerkinElmer, USA).

\section{Protective effect of Pm-GCH on adriamycin-injured 293T/D cells in vitro}

First, the injury cell model of 293T cells (293T/D) treated with doxorubicin $(6 \mu \mathrm{g} / \mathrm{ml})$ was established. The 293T/D cells were divided into four groups, including the GC, H, GCH and Pm-GCH groups. 293T/D cells were treated with GC, H, GCH and Pm-GCH (H concentration $10 \mathrm{mg} / \mathrm{L}$ ) for $24 \mathrm{~h}$. A CCK 8 cell viability test and staining of dead cells were carried out. CCK8 experiment: 293T/D cells were cultured in 96-well plates and then incubated with GC, H, GCH and Pm$\mathrm{GCH}(\mathrm{H}$ concentration $10 \mathrm{mg} / \mathrm{L})$ for $24 \mathrm{~h}$. Ten microliters of CCK solution was added to each well for $2 \mathrm{~h}$. The absorbance at $450 \mathrm{~nm}$ was detected by a UV-Vis spectrophotometer. Staining test of living and dead cells: 293T/D cells were cultured in 6-well plate culture, 
and incubated with GC, H, GCH, and Pm-GCH (H concentration $10 \mathrm{mg} / \mathrm{L}$ ) for further culture for $24 \mathrm{~h}$. According to the instructions of Cytotoxicity Assay Kit (C2015M, Beyotime, China), $0.5 \mathrm{ml}$ staining solution (Calcein-AM $2 \mu \mathrm{M}$, PI $4.5 \mu \mathrm{M}$ ) was added to each well and incubated at $37^{\circ} \mathrm{C}$ for $5 \mathrm{~min}$. The cells were observed and photographed under an inverted fluorescence microscope.

\section{Establishment of a mouse model of SRNS}

Six-week-old female C57 mice were obtained from Hunan SJA Laboratory Animal Co., Ltd. All animal experiment schemes were approved by the Animal Use and Care Committee of Central South University. A mice model of SRNS was constructed according to the literature. A single injection of doxorubicin $(6.2 \mathrm{mg} /$ $\mathrm{kg}$ ) was given through the tail vein, and hydrocortisone $(25 \mathrm{mg} / \mathrm{kg} /$ day, 7 days) was injected into the hip muscle. Twenty-four-hour urine was collected on the 7th, 8th, and 9th days after injection for quantitative detection of urine protein. When the $24 \mathrm{~h}$ urine protein quantity was $\geq 100 \mathrm{mg} / \mathrm{kg}$ and lasted for more than 3 days, the model was considered to be successful.

\section{The distribution of $\mathrm{Pm}-\mathrm{GCH}$ in vivo}

Initially, $100 \mu \mathrm{l} \mathrm{GCH-cy5}$ and Pm-GCH-cy5 $(\mathrm{H}, 1 \mathrm{mg} /$ $\mathrm{ml}$ ) were injected through the tail vein of SRNS mice. The SRNS mice were anesthetized at 6, 24, and $48 \mathrm{~h}$ after injection and imaged with the In Vivo Imaging System (PerkinElmer, USA). Meanwhile, mice were euthanized at 6, 24 and $48 \mathrm{~h}$ after injection. The heart, liver, spleen, lung, kidney and brain were collected for fluorescence imaging by an In Vivo Imaging System (PerkinElmer, USA).

\section{The protective effect of $\mathrm{Pm}-\mathrm{GCH}$ in vivo}

Then, $100 \mu \mathrm{l} \mathrm{GC}, \mathrm{H}, \mathrm{GCH}$ and Pm-GCH $(\mathrm{H}, 1 \mathrm{mg} /$ $\mathrm{ml}$ ) were injected daily through the tail vein of SRNS mice for 3 consecutive days. Urine was collected for 24-h urinary protein quantitation. The concentration of urine protein was detected with a BCA Protein Assay Kit (P0012S, Beyotime, China). After 12 days, all SRNS mice were euthanized, and fresh whole blood was taken for routine blood and kidney function. Hematological indices (RBCs, Hb, WBCs, PLTs) were determined by an automatic blood cell analyzer (Mindray, China). The liver function index (ALT, AST) and renal function index (CREA, BUN) were detected by a Leadman Diagnostic Kit (Leadmanbio, China). Kidney, lung, liver, spleen, heart and femur samples were fixed with $4 \%$ paraformaldehyde and embedded in paraffin. Ultrathin sections were used for HE and
Masson staining with a hematoxylin-eosin staining Kit (G1120, Solarbio, China) and Masson's trichrome stain kit (G1340, Solarbio, China).

\section{Transmission electron microscope imaging}

The kidney tissues $\left(<1 \mathrm{~mm}^{3}\right)$ were fixed in $2.5 \%$ glutaraldehyde at $4{ }^{\circ} \mathrm{C}$ overnight, and then fixed in $1 \%$ osmic acid for $1-2 \mathrm{~h}$. The samples were dehydrated with gradient concentrations of ethanol. Then, kidney samples were treated with acetone for $20 \mathrm{~min}$ and embedded with an Embed 812 Embedding Kit (GE14120, EMS, USA). The samples were sliced with an ultra-thin slicer to obtain sections of $70-90 \mathrm{~nm}$. The sections were stained with uranyl acetate and alkaline lead citrate and observed using transmission electron microscopy (Hitachi, Japan).

\section{Immunofluorescent staining}

Paraffin sections were dewaxed with xylene and hydrated with different gradients of alcohol. Sections were prepared in citrate buffer at $95{ }^{\circ} \mathrm{C}$ for antigen repair. Hydrogen peroxide $(3 \%)$ was added to the sections to remove endogenous peroxidase activity, and 5\% BSA was added to block the nonspecific binding site. The sections were incubated with PLA2 primary antibody $(1: 200)$ at $37{ }^{\circ} \mathrm{C}$ for $2 \mathrm{~h}$. After washing with PBS, FITC-labeled goat antimouse secondary antibody (1:500) was added on the sections at $37^{\circ} \mathrm{C}$ for $2 \mathrm{~h}$. After washing with PBS, the sections were incubated with C2 primary antibody (1:200) and CY3-labeled goat anti-rabbit secondary antibody (1:500) at $37{ }^{\circ} \mathrm{C}$ for $2 \mathrm{~h}$. Finally, kidney sections were restained with DAPI and photographed with a fluorescence microscope.

\section{Micro-CT analysis}

After the application of $\mathrm{Pm}-\mathrm{GCH}$, the femurs of mice were taken for micro-CT scanning (SkyScan1276, Bruker, Germany). The following parameters were obtained and analyzed: BV, bone volume; TV, tissue volume; BV/TV, relative bone volume; $\mathrm{Tb}$. Th, trabecular thickness; and $\mathrm{Tb} . \mathrm{N}$, trabecular number.

\section{Statistical analysis}

SPSS software 18.0 was used for statistical analysis. Data were presented as the mean \pm standard deviation. Comparisons between groups were analyzed with one-way analysis of variance (ANOVA) and Tukey's post test. One asterisk (*) represents $\mathrm{p}<0.05$, and a double asterisk (**) represents $\mathrm{p}<0.01$. 


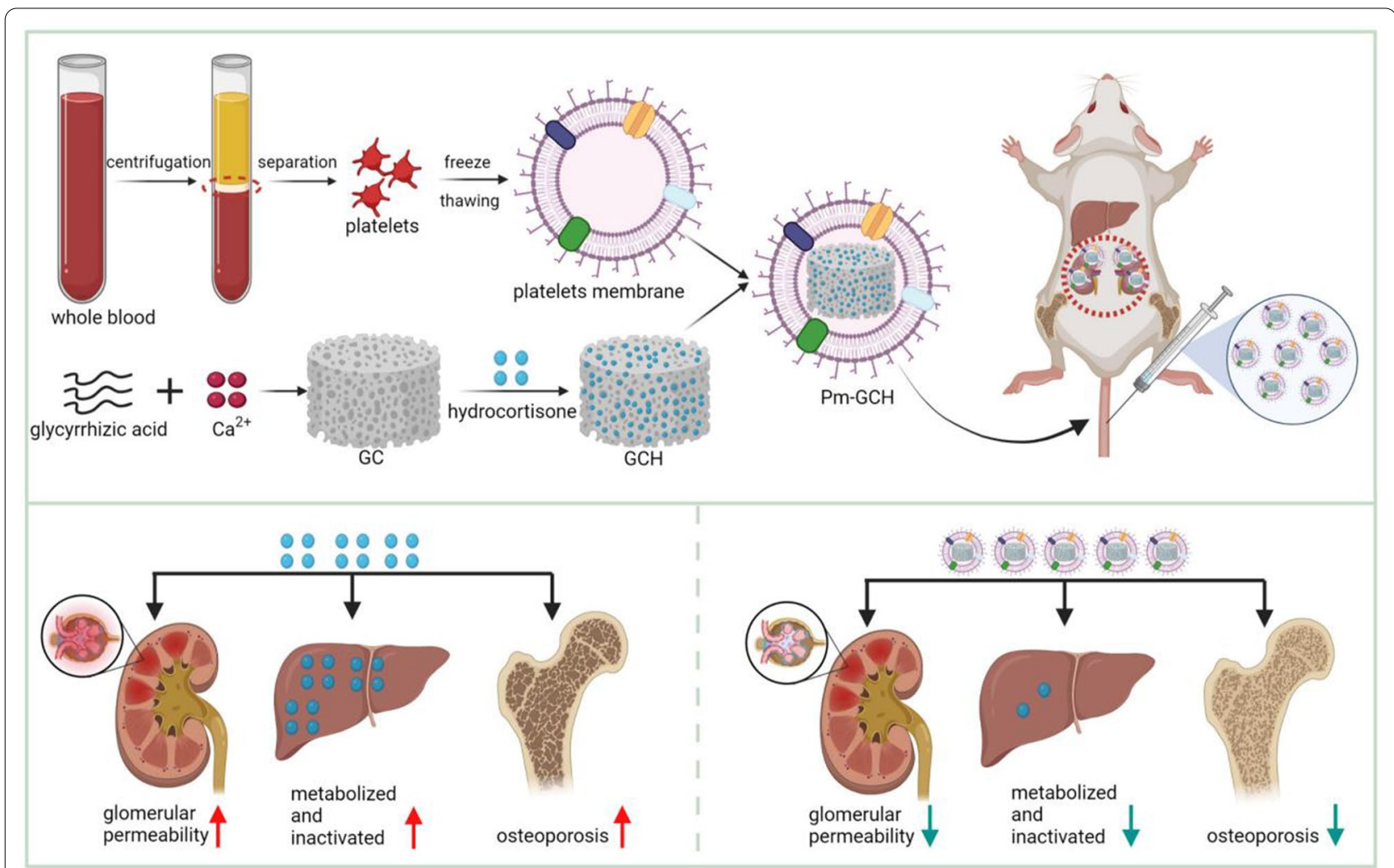

Fig. 1 Construction of Pm-GCH and its targeted therapeutic mechanism in SRNS by inhibitting inflammation and osteoporosis

\section{Results and discussion}

\section{Construction and characterization of Pm-GCH}

As shown in Fig. 1, the preparation process of Pm$\mathrm{GCH}$ mainly includes the generation of a metalorganic framework (GC) constructed by glycyrrhizic acid and $\mathrm{Ca}^{2+}$ loading hydrocortisone to form a $\mathrm{GCH}$ nanocore. The shell structure, platelet membrane vesicle $(\mathrm{Pm})$, wrapped $\mathrm{GCH}$ to form the final core-shell structure of Pm-GCH. First, the changes in the size, zeta potential, and morphology of $\mathrm{Pm}-\mathrm{GCH}$ were determined. In Fig. 2A, the TEM image indicates that Pm-GCH had a typical core-shell structure. The particle size of GCH was approximately $95 \pm 5 \mathrm{~nm}$. After fusion with $\mathrm{Pm}$, the particle size of $\mathrm{Pm}-\mathrm{GCH}$ was $110 \pm 9 \mathrm{~nm}$. In Fig. 2B, the dynamic light scattering data show that the particle sizes of $\mathrm{GCH}, \mathrm{Pm}$, and Pm$\mathrm{GCH}$ are $98 \pm 13 \mathrm{~nm}, 102 \pm 9 \mathrm{~nm}$ and $121 \pm 12 \mathrm{~nm}$, respectively. In Fig. $2 \mathrm{C}$, the zeta potentials of $\mathrm{GCH}$ and Pm were $-9 \pm 1.2 \mathrm{mV}$ and $-21 \pm 1.6 \mathrm{mV}$, respectively, while the zeta potential of Pm-GCH was $-19 \pm 0.9 \mathrm{mV}$, close to the zeta potential of $\mathrm{Pm}$, which may be due to the charge shielding effect caused by $\mathrm{Pm}$ encapsulation, and demonstrates the successful encapsulation of Pm-GCH. To assess the dispersion and stability of $\mathrm{Pm}-\mathrm{GCH}$, we monitored the hydrodynamic size of
Pm-GCH for two weeks in PBS, DMEM and 10\% FBS, and there was no significant change in particle size. The above results indicated that $\mathrm{Pm}-\mathrm{GCH}$ possessed good stability in physiological solution (Fig. 2D). In the UV-Vis absorption spectrum (Fig. 2E), Pm-GCH had absorption peaks at $200 \mathrm{~nm}, 235 \mathrm{~nm}$ and $252 \mathrm{~nm}$, respectively, in accordance with the characteristic absorption peaks of Pm, hydrocortisone and glycyrrhizic acid, respectively. In the SDS-PAGE electrophoresis image, the protein profile of $\mathrm{Pm}-\mathrm{GCH}$ was similar to that of $\mathrm{Pm}$, which confirmed once again that the $\mathrm{Pm}$ protein was successfully transferred to $\mathrm{Pm}-\mathrm{GCH}$ (Fig. 2F).

\section{Hemocompatibility and immune escape effect of Pm-GCH}

First, the hemocompatibility of $\mathrm{Pm}-\mathrm{GCH}$ was evaluated by a hemolysis test. Different concentrations of $\mathrm{GCH}$ and Pm-GCH were added to 5\% RBCs for $2 \mathrm{~h}$. After centrifugation, the absorbance of the supernatant was detected. As indicated in Fig. 3A, the hemolysis rate of GCH $(200 \mu \mathrm{g} / \mathrm{ml})$ was approximately $5.4 \%$, while the hemolysis rate of $\mathrm{Pm}-\mathrm{GCH}$ at various concentrations was less than $1 \%$. This finding suggests that Pm-GCH has good blood compatibility after being 

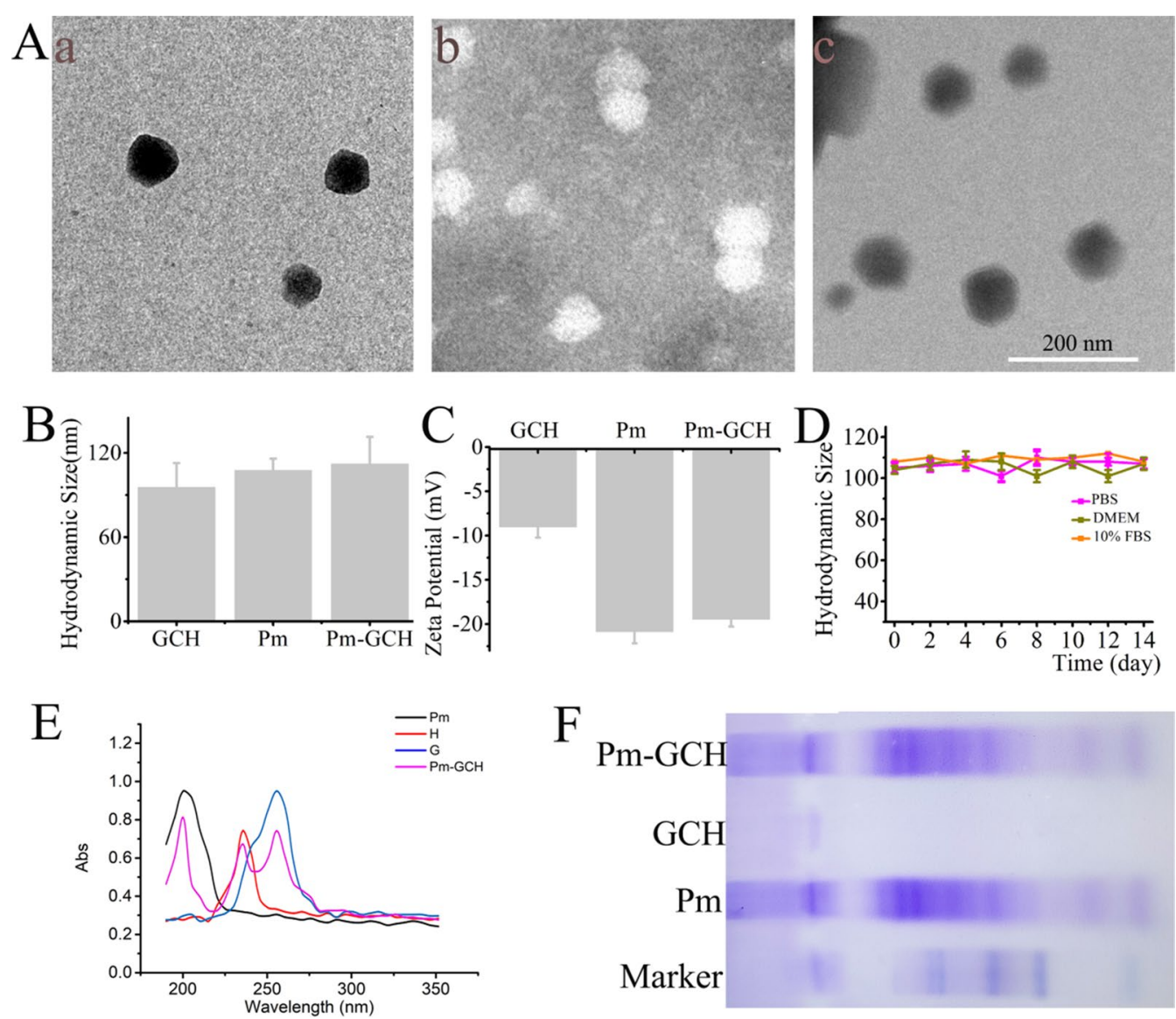

Fig. 2 Characterization of Pm-GCH. A TEM-image analysis of GCH (a), Pm vesicles (b), and Pm-GCH (c). Scale bar: 200 nm. B Hydrodynamic size and C zeta potential of GCH, Pm and Pm-GCH. D The size change of Pm-GCH over 14 days in PBS, DMEM and 10\% FBS. E UV-vis spectra of Pm, H, G and Pm-GCH. F The profile of platelet membrane proteins was detected by SDS-PAGE analysis

encapsulated by the platelet membrane and can be used for intravenous administration.

Second, the immune evasive ability of Pm-GCH-Cy5 was investigated by detecting the antiphagocytic effect on macrophages. As shown in Fig. 3B and C, a large amount of Cy5 (red fluorescence) was present in macrophages in the $\mathrm{GCH}$-treated group. In contrast, the red fluorescence in the Pm-GCH-treated macrophages was significantly reduced, indicating that the effect of macrophages on the phagocytosis of Pm-GCH was significantly reduced after platelet membrane vesicle camouflage. The above results confirm that $\mathrm{GCH}$ with platelet membrane encapsulation can evade the identification of macrophages and reduce the clearance of the immune system.

\section{The drug loading and release of $\mathrm{Pm}-\mathrm{GCH}$}

As a metal-organic material, GC prepared with glycyrrhizin and $\mathrm{Ca}^{2+}$ as raw materials has high specific surface area and can serve as an ideal carrier for drugs. As indicated in Fig. 4A, the EE and LE of hydrocortisone load on GC are $96.7 \%$ and $38.7 \%$, respectively. Furthermore, an ideal drug carrier should also achieve efficient drug release at the targeted site. During this research, $\mathrm{pH} 7.4$ and $\mathrm{pH} 6.5$ simulated a neutral circulation environment and an acidic inflammatory microenvironment, respectively. As indicated in Fig. 4B, C, Pm-GCH released hydrocortisone and glycyrrhizic acid in a pH-dependent manner. Compared with results at $\mathrm{pH} 7.4$, hydrocortisone and glycyrrhizic acid were released more easily at $\mathrm{pH} 6.5$, which demonstrates that $\mathrm{Pm}-\mathrm{GCH}$ is particularly useful for drug delivery under renal inflammation conditions in steroid-resistant nephrotic syndrome.

\section{Biocompatibility and protective effect of $\mathrm{Pm}-\mathrm{GCH}$ in vitro} First, the biocompatibility of $\mathrm{Pm}-\mathrm{GCH}$ in vitro was assessed in 293T and HKC-8 cells. Cells were treated with GC, H, GCH, and Pm-GCH for 24,48 , and $72 \mathrm{~h}$ at $37{ }^{\circ} \mathrm{C}$. As shown in Fig. $5 \mathrm{~A}$, the viability of $293 \mathrm{~T}$ 

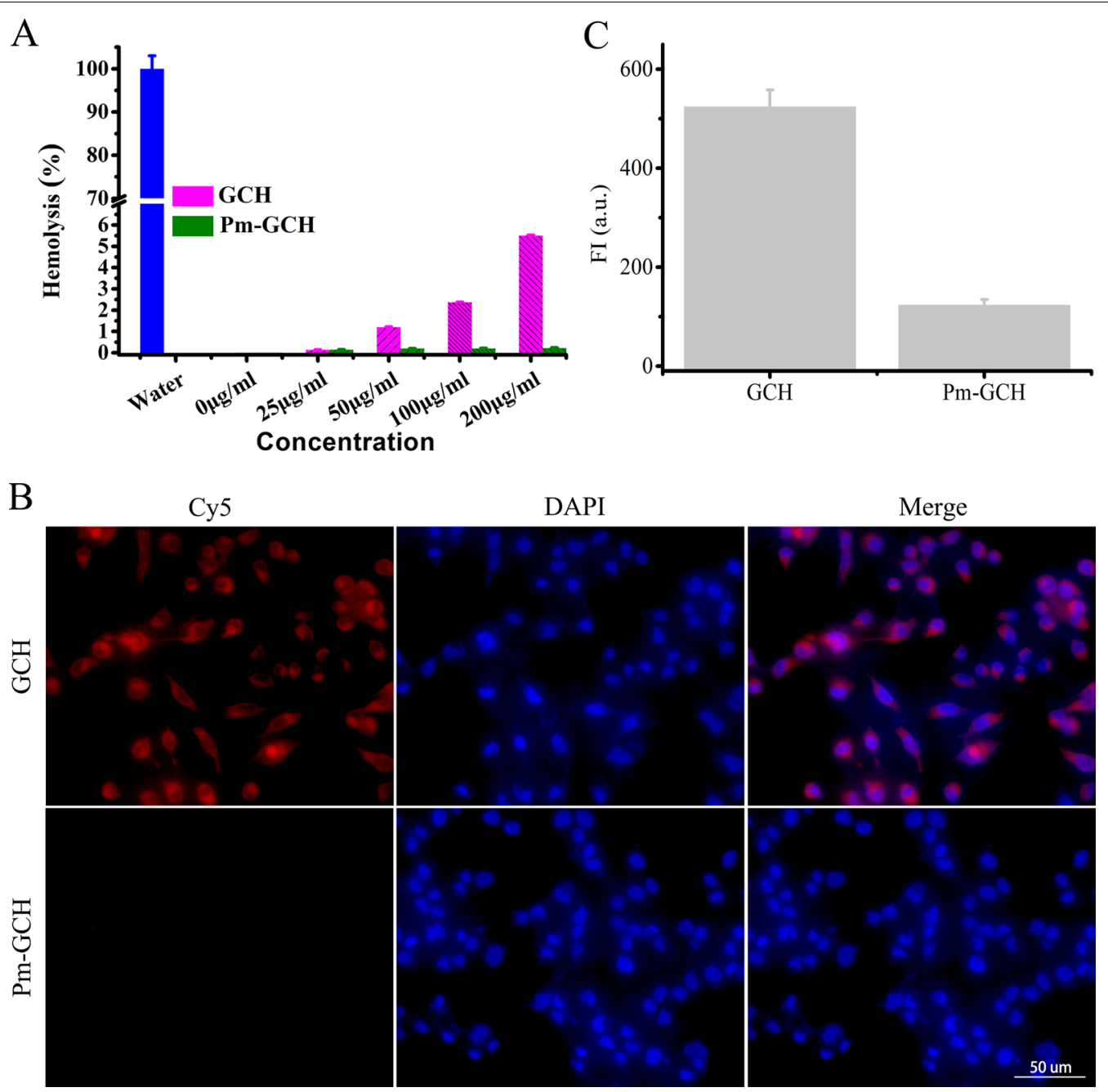

Fig. 3 The hemocompatibility and immune escape effect of Pm-GCH. A The hemolysis rate of RBCs with different concentrations of GCH and $\mathrm{Pm}-\mathrm{GCH}$. B The fluorescence images of macrophages aftter treated with GCH and Pm-GCH for $6 \mathrm{~h}$. $\mathbf{C}$ The fluorescence intensity of macrophage lysates after treated with GCH-Cy5 and Pm-GCH-Cy5 for $6 \mathrm{~h}$
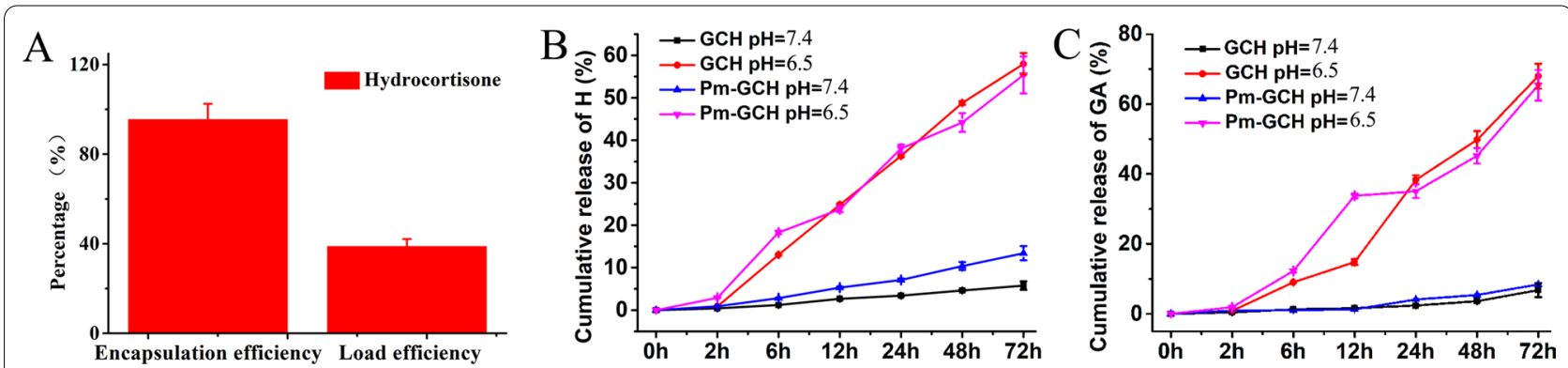

Fig. 4 A The EE and LE of hydrocortisone. B Cumulative release ratio of $\mathrm{H}$ from $\mathrm{GCH}$ and $\mathrm{Pm}-\mathrm{GCH}$ at different $\mathrm{pH}$ values $(6.5,7.4)$. C Cumulative release ratio of GA from GCH and Pm-GCH at different $\mathrm{pH}$ values $(6.5,7.4)$ 


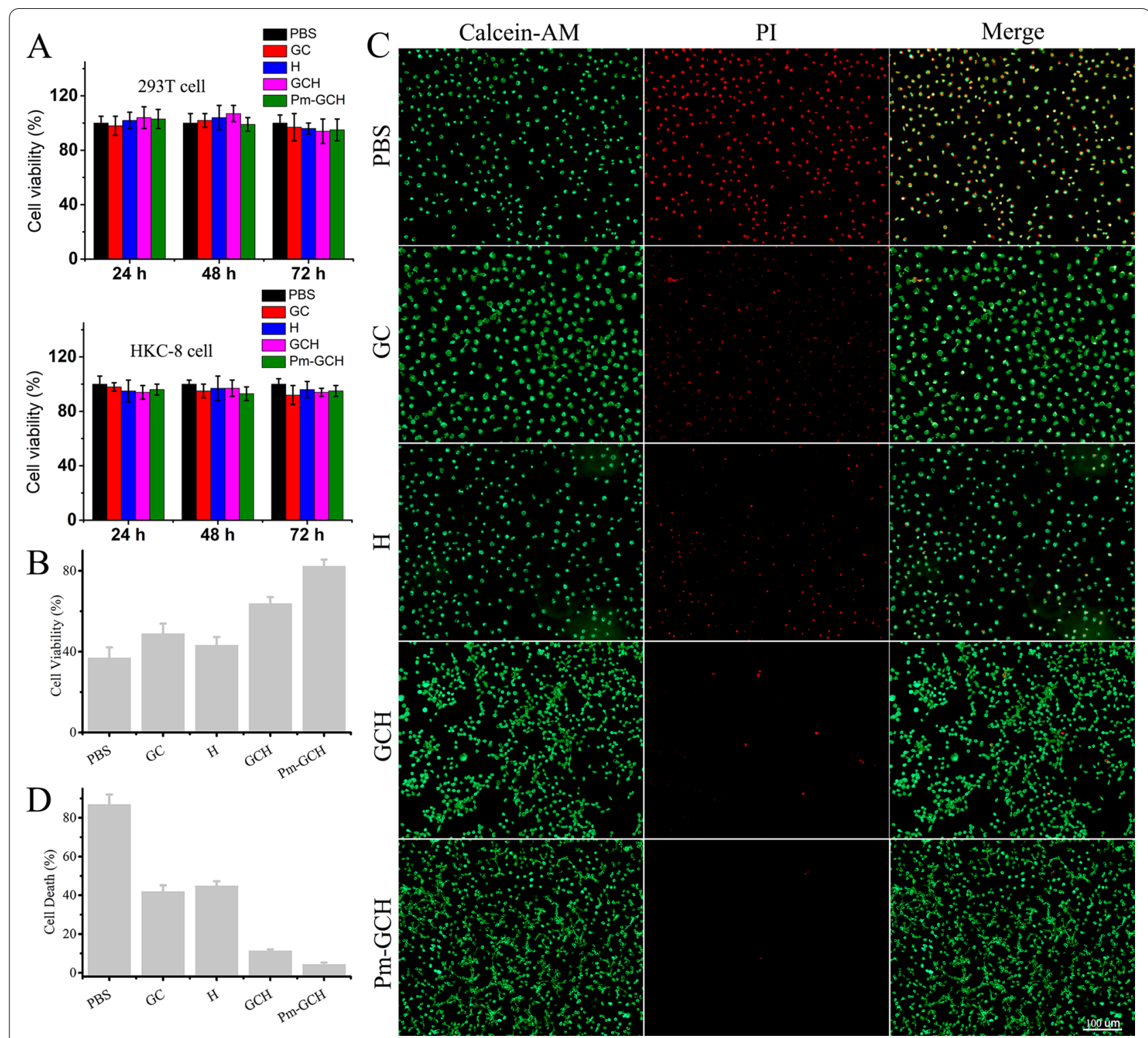

Fig. 5 A The viability of 293T and HKC-8 cells was detected by CCK8 assays after administration of PBS, GC, H, GCH and Pm-GCH for 24, 48 and $72 \mathrm{~h}$. B The viability of 293T/D cells was detected by CCK8 assays after administration of PBS, GC, H, GCH and Pm-GCH for $24 \mathrm{~h}$. C Live/dead staining of 293T/D cells after various treatments (PBS, GC, H, GCH and Pm-GCH) for 24 h. D Semiquantitative ratio of cell death

and HKC-8 cells incubated with Pm-GCH for $72 \mathrm{~h}$ was 95.5 and $94.3 \%$, respectively. The CCK8 assay indicated that $\mathrm{Pm}-\mathrm{GCH}$ showed no significant cytotoxicity and had good biocompatibility. To explore the protective effect of $\mathrm{Pm}-\mathrm{GCH}$ in vitro, an injuried $293 \mathrm{~T}$ cell model $(293 \mathrm{~T} / \mathrm{D})$ treated with doxorubicin $(6 \mu \mathrm{g} / \mathrm{ml})$ was established. The 293T/D cells were divided into four groups: the GC, H, GCH and Pm-GCH groups. As shown in Fig. $5 \mathrm{~B}$, in the CCK-8 assays, $\mathrm{GC}, \mathrm{H}, \mathrm{GCH}$, and $\mathrm{Pm}-\mathrm{GCH}$ all enhanced
293T/D cell viability to varying degrees. At the same time, Pm-GCH exerted the strongest cell protective effect. The protective effect of $\mathrm{Pm}-\mathrm{GCH}$ in vitro was evaluated by living/dead cell staining. After 293T/D cells were treated with GC, H, GCH, and Pm-GCH, cells were stained with calcein-AM/PI staining solution. The living cells showed green fluorescence with calcein-AM staining, and the dead cells showed red fluorescence with PI staining. The staining results of living and dead cells were consistent with those of the 
CCK-8 assay (Fig. 5C, D). After Pm-GCH treatment, the number of apoptotic/dead cells with red fluorescence was significantly reduced, which indicated that $\mathrm{Pm}-\mathrm{GCH}$ showed the best protective effect in vitro. It was reported that glycyrrhizic acid ameliorated cisplatin-induced nephrotoxicity by inhibiting the cytoplasmic localization and release of HMGB1 [36]. Glycyrrhizic acid was aslo found to have a protective effect on renal tubular epithelial cell proliferation and oxidative stress induced by high glucose by increasing the expression of AMPK, SIRT1, and Mn-SOD [37]. In addition, hydrocortisone could inhibit doxorubicininduced cardiomyocyte apoptosis by promoting the expression of pro-survival protein Bcl-XL [38]. In conclusion, the protective effect of $\mathrm{Pm}-\mathrm{GCH}$ on renal epithelial cells lies in the nonspecific targeting effect of $\mathrm{Pm}$ on injured cells and the combined application of glycyrrhizic acid and hydrocortisone.

\section{Biodistribution of $\mathrm{Pm}-\mathrm{GCH}$ in vivo}

First, a mouse model of SRNS was constructed. When the $24 \mathrm{~h}$ urine protein was $\geq 100 \mathrm{mg} / \mathrm{kg}$ and lasted for more than 3 days, the model was considered to be successful. Then, $100 \mu \mathrm{l}$ of PBS, GCH-Cy5 and Pm$\mathrm{GCH}-\mathrm{Cy} 5$ was injected daily through the tail vein. Six to $48 \mathrm{~h}$ after injection, the SRNS mice were imaged by an IVIS ${ }^{\circledR}$ Spectrum In Vivo Imaging System (Fig. 6A). Meanwhile, the SRNS mice were euthanized, and the kidney, heart, liver, spleen and lung were collected and imaged by an IVIS ${ }^{\circledR}$ Spectrum In Vivo Imaging System (Fig. 6B, C). As shown in Fig. 6, less GCH-Cy5 reached the inflammation site of the kidney from 6 to $48 \mathrm{~h}$. Because of the targeting of inflammation and immune escape, the accumulation of Pm-GCH-Cy5 in the inflammation site of the kidney increased significantly at $24 \mathrm{~h}$. Meanwhile, GCH-Cy 5 showed less accumulation in the kidney and was mainly concentrated in the lung and liver. In contrast to $\mathrm{GCH}-\mathrm{Cy} 5$, the content of $\mathrm{Pm}-\mathrm{GCH}-\mathrm{Cy} 5$ in the lung and liver was obviously lower. Notably, Pm-GCH-Cy5 showed greater accumulation than $\mathrm{GCH}-\mathrm{Cy} 5$ in the kidney. Two weeks after injection, there was no Pm-GCH and still a small amount of $\mathrm{GCH}$ distributed in the mice, which is mainly because that GCH tended to accumulate in the body and blocked the pulmonary vessels. The above results suggest that the immune escape of $\mathrm{Pm}-\mathrm{GCH}-\mathrm{Cy} 5$ prolongs the blood circulation time and achieves targeted aggregation in kidney sites under the effect of Pm.

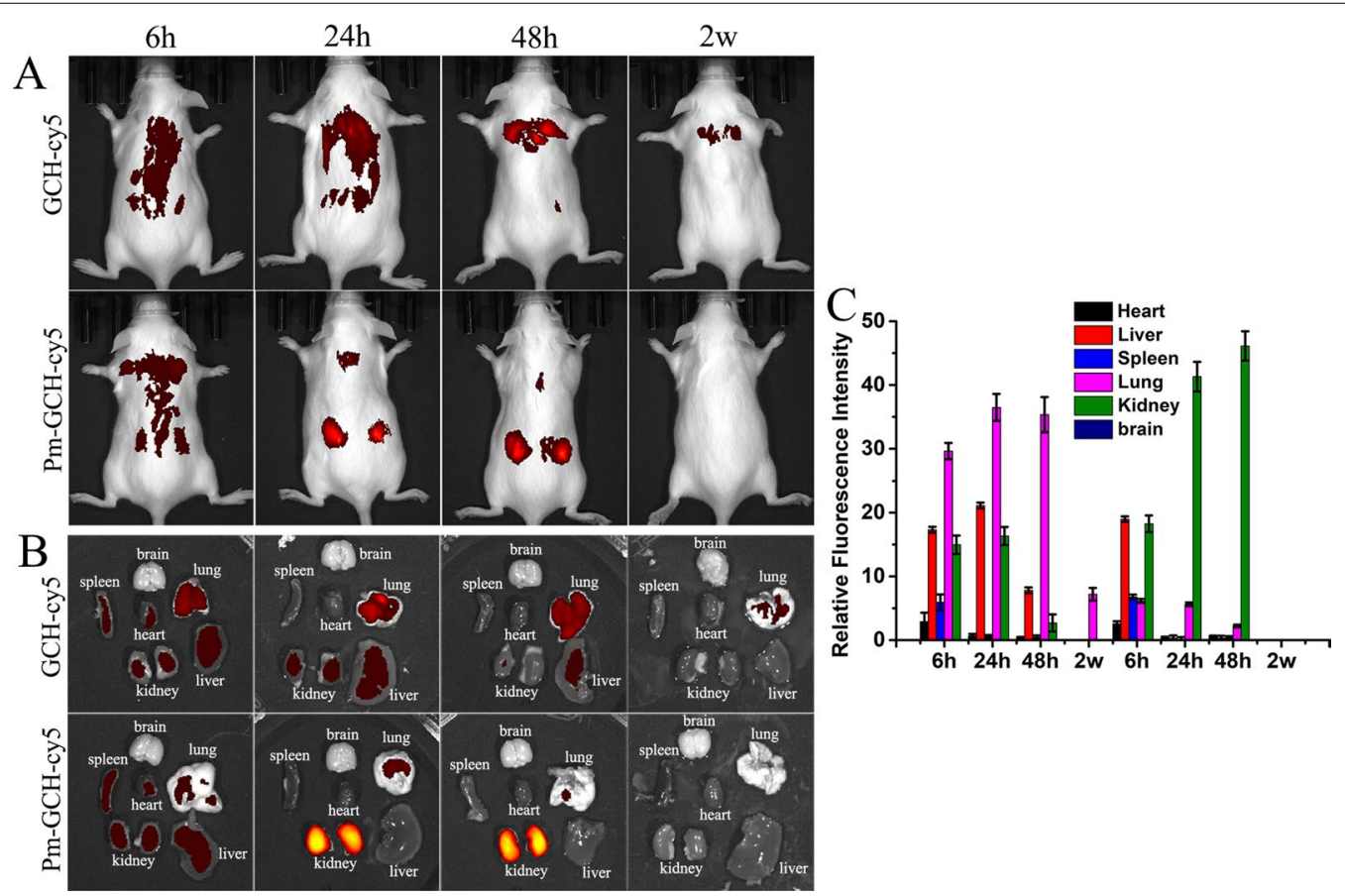

Fig. 6 In vivo targeting potential of Pm-GCH. A The biodistribution images of the whole body of mice. B Fluorescence images of main organs (brain, heart, liver, spleen, lung, and kidney) were measured at 6 h, 24 h, 48 h and 2 week after intravenous injection of GCH and Pm-GCH in SRNS mice. B Semiquantitative assessment of fluorescent signals in brain, heart, liver, spleen, lung, and kidney 


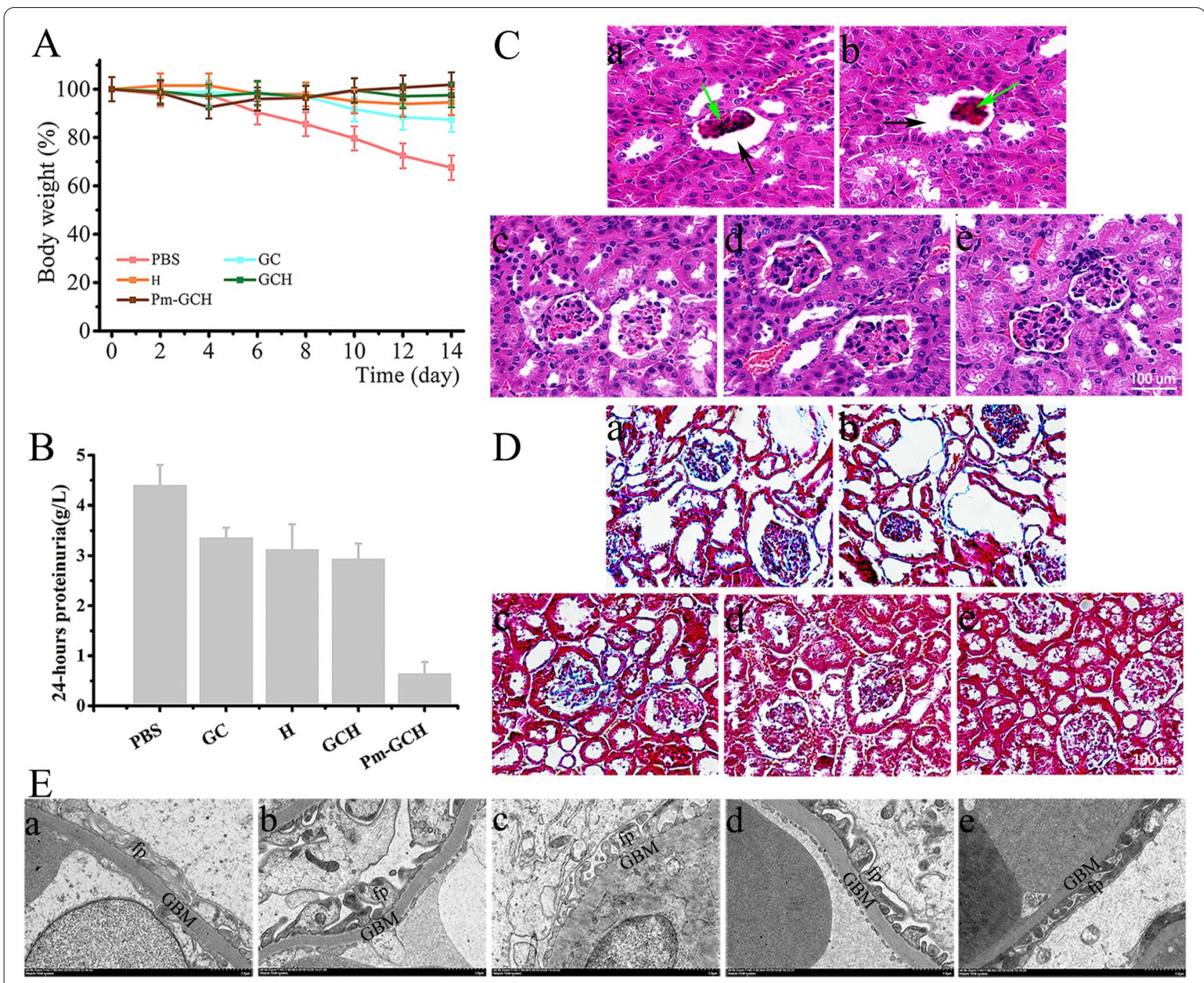

Fig. 7 A Body weight alterations in the mice with SRNS during GC, H, GCH and Pm-GCH treatment. B Quantification of 24-h proteinuria after GC, H, GCH and Pm-GCH treatment. Representative images of kidneys after H\&E staining (C) and Masson staining (D) after intravenous injection of (a) PBS, (b) GC, (c) H, (d) GCH and (e) Pm-GCH, respectively. Black arrows, enlarged Bowman's space; green arrows, glomerular sclerosis. E The ultrastructure of the glomerular filtration barrier was assessed by transmission electron microscopy. fp foot process, GBM glomerular basement membrane

The renal protection of $\mathrm{Pm}-\mathrm{GCH}$ in vivo

Next, the renal protective effects of Pm-GCH in vivo in the SRNS mice were evaluated. When the $24 \mathrm{~h}$ urine protein quantity was $\geq 100 \mathrm{mg} / \mathrm{kg}$ and lasted for more than 3 days, the model was considered to be successful. PBS, GC, H, GCH and Pm-GCH $(100 \mu \mathrm{l})$ were administered through the tail vein. The body weight and $24 \mathrm{~h}$ urine protein of the mice with SRNS were monitored continuously within 14 days (Fig. 7A, B). The mice with SRNS showed greater albuminuria and weight loss. GC, H, GCH and Pm-GCH all reduced albuminuria and improved body weight to some extent. Notably, Pm-GCH had the most significant effect. Furthermore, the results of HE and Masson staining showed glomerular sclerosis, enlarged Bowman's space and increased collagen deposition in the kidneys of the mice with SRNS (Fig. 7C, D). In the $\mathrm{Pm}-\mathrm{GCH}$ group, glomerular sclerosis and collagen deposition were significantly improved. In addition, the ultrastructure of the glomerular filtration barrier was observed by transmission electron microscopy. As shown in Fig. 7E, podocyte foot process (fp) effacement was observed in the mice with SRNS, resulting in fusion of the podocyte foot process, loss of slit diaphragm, and microvillous transformation. Interestingly, Pm-GCH reproduced the foot process of the podocyte and slit diaphragm. The pathogenesis of nephrotic syndrome is complex, and inflammation 


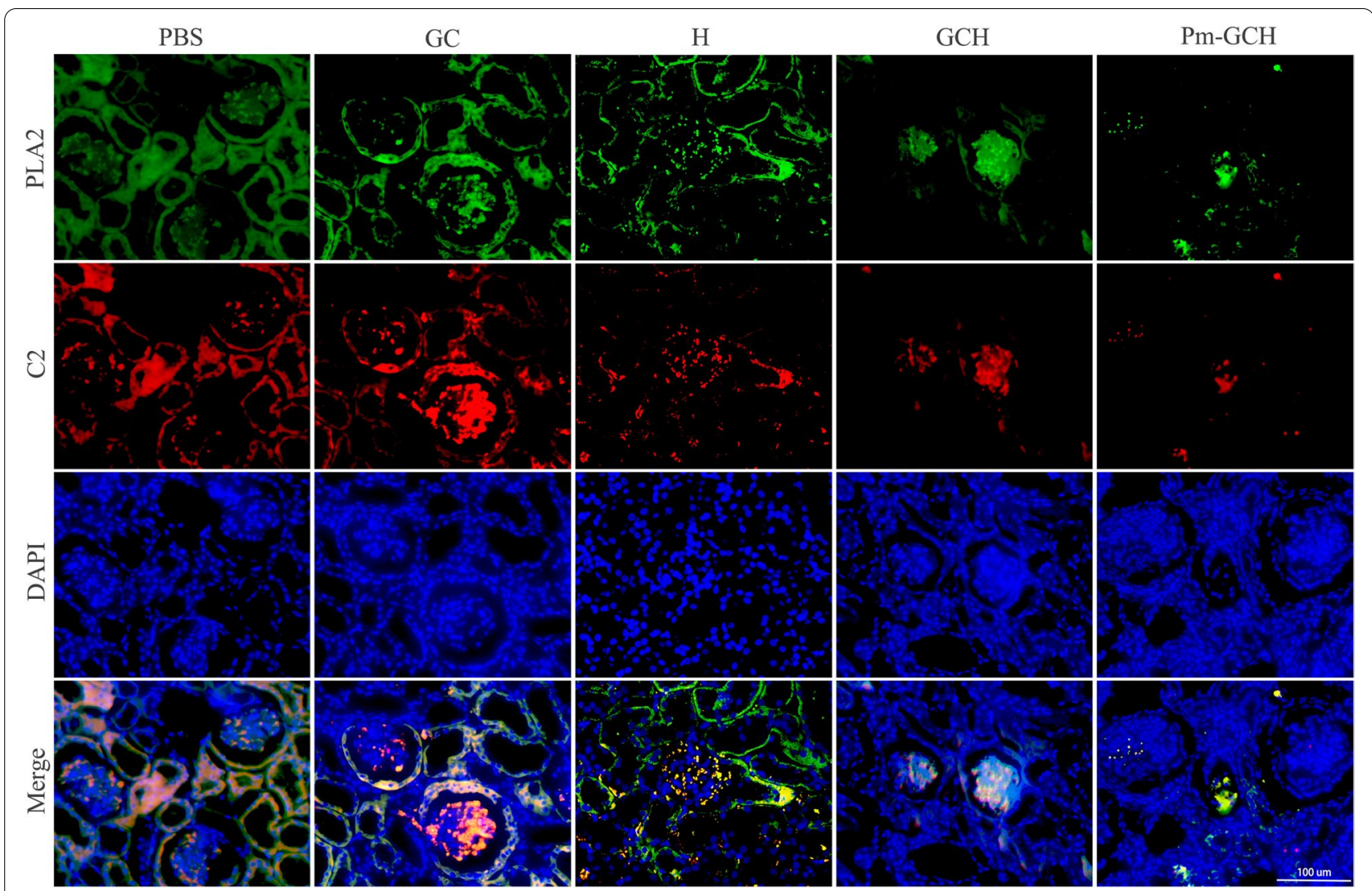

Fig. 8 Expression pattern of inflammatory cytokines (PLA2 and C2) analyzed by immunofluorescence staining in the kidney

has been proven to be an important cause. During nephrotic syndrome, the abnormal expression of inflammation-related protein PLA2 and complement $\mathrm{C} 2$ activates the inflammatory response and aggravates renal function injury [39]. PLA2 can breakdown phospholipids to produce arachidonic acid, which is further metabolized to produce cyclooxygenase and prostaglandin E2, inducing an inflammatory response and being the trigger point of the inflammatory response [40]. Complement C2 is the rate-limiting component of the complement activation cascade [41]. To study the anti-inflammatory mechanism of $\mathrm{Pm}-\mathrm{GCH}$, we detected inflammatory cytokines (PLA2, C2) in the kidneys by immunofluorescence staining. As shown in Fig. 8, in the kidneys of the mice with SRNS, inflammatory cytokines (PLA2, C2) were highly expressed. In the Pm-GCH group, the levels of inflammatory cytokines (PLA2 and C2) were downregulated. The above results suggested that $\mathrm{Pm}-\mathrm{GCH}$ improved the inflammatory response by inhibiting the activity of PLA2 and C2.

\section{The anti-osteolytic effect of $\mathrm{Pm}-\mathrm{GCH}$ in vivo}

Large amounts of glucocorticoids were used in the modeling of the mice with SRNS. Long-term use of high doses of glucocorticoids leads to osteoporosis. It was reported that glycyrrhizic acid promoted osteogenic differentiation of bone marrow stromal cells by activating the $\mathrm{Wnt} / \beta$-catenin signaling pathway [42]. In addition, as an $11 \beta$-hydroxysteroid dehydrogenase inhibitor, glycyrrhizic acid has a protective effect on glucocorticoid-induced osteoporosis [43]. To investigate whether $\mathrm{Pm}-\mathrm{GCH}$ improves glucocorticoidinduced osteolysis, we performed CT imaging of the mice femurs (Fig. 9A). Micro-CT 3D reconstructions indicated a decrease in the number of femoral trabeculae and the thickness of the femoral shaft in the mice with SRNS. However, as shown in Fig. 9B, the mice treated with $\mathrm{Pm}-\mathrm{GCH}$ had significantly higher trabecular bone volume per total volume (BV/TV) values than the mice with SRNS. Furthermore, trabecular thickness $(\mathrm{Tb} . \mathrm{Th})$ and trabecular number $(\mathrm{Tb}$. $\mathrm{N})$ in the Pm-GCH-treated mice were significantly 


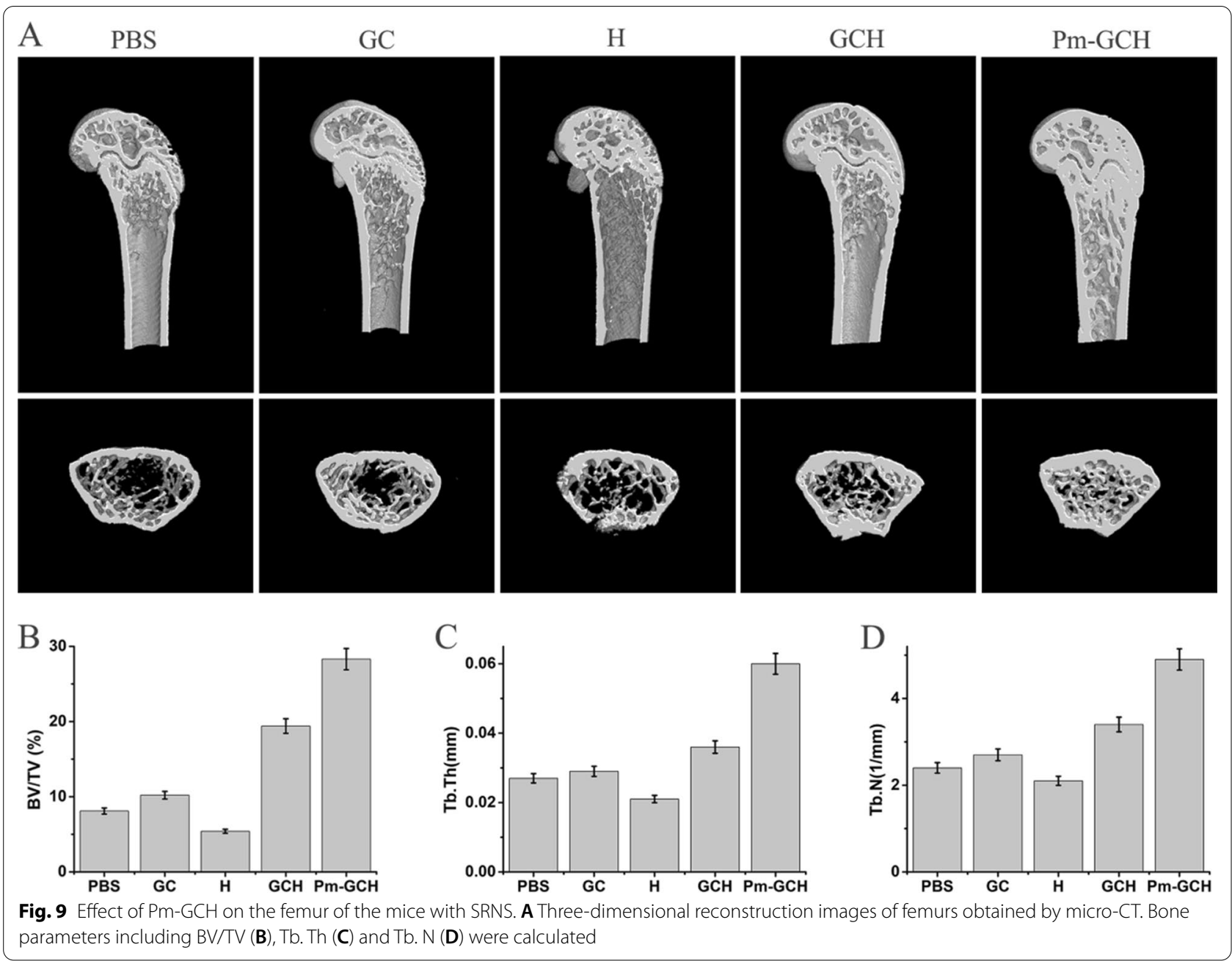

increased (Fig. 9C, D). These results indicated that PM-GCH significantly improved osteolysis induced by glucocorticoids.

\section{The biocompatibility of Pm-GCH in vivo}

The biocompatibility of Pm-GCH was also evaluated in vivo. As shown in Fig. 10A, there were no obvious differences in the hematological index (RBCs, $\mathrm{Hb}, \mathrm{WBCs}, \mathrm{PLTs}$ ) or liver function index (ALT, AST) after GC, H, GCH and Pm-GCH treatment. However, $\mathrm{Pm}-\mathrm{GCH}$ improved the elevation of the renal function index (CREA, BUN) induced by SRNS. Moreover, HE staining of the heart, liver, spleen and lung showed that Pm-GCH did not change the histological structures of major organs (Fig. 10B). These results further verify that $\mathrm{Pm}-\mathrm{GCH}$ possesses good biocompatibility.

\section{Conclusion}

In this study, MOFs were constructed by glycyrrhizic acid and $\mathrm{Ca}^{2+}$, loaded with hydrocortisone, and platelet membrane vesicles were used for camouflage to target the inflammatory sites of the kidney in an SRNS model. Glycyrrhizic acid plays an anti-inflammatory role, an immunomodulatory role, and a steroid-like role, enhances the effect of glucocorticoids and reduces the side effects of glucocorticoid application. Glucocorticoids interfere with arachidonic acid metabolism, inhibit the synthesis of cytokines and rapidly inhibit inflammation and the immune response to improve glomerular membrane permeability, diuresis and eliminate urinary protein. Nanoscale platelet membrane vesicles compete with platelets in vivo to bind to inflammatory sites, reduce platelet activation and weaken the inflammatory 

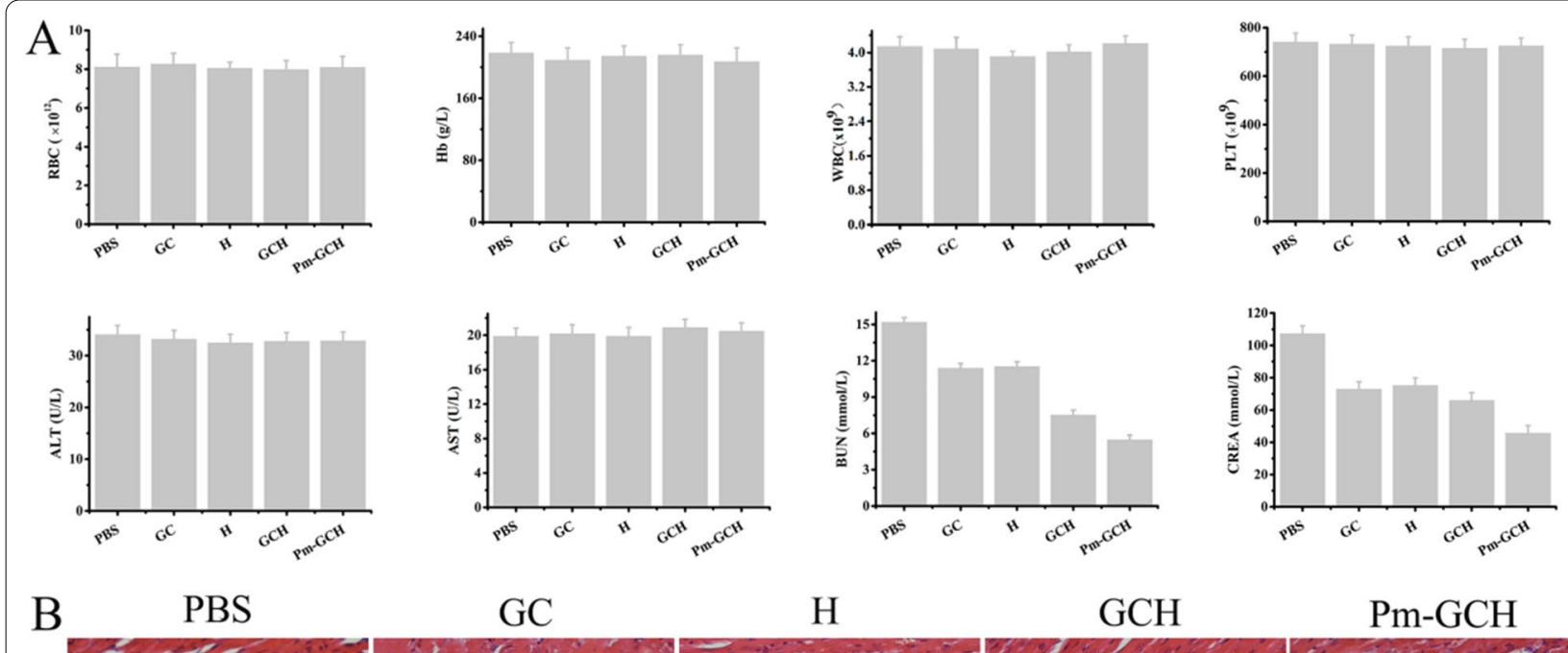

GC

$\mathrm{H}$
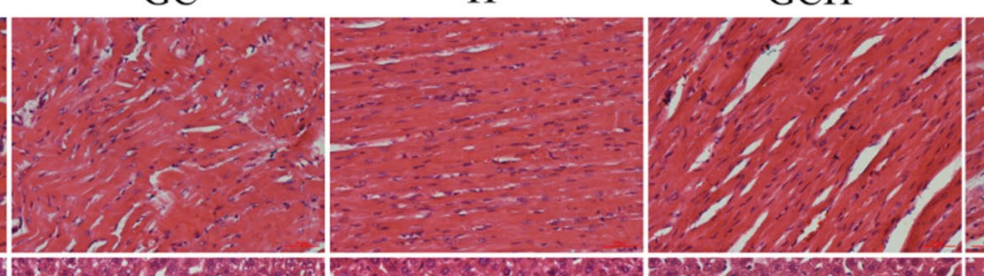

Pm-GCH
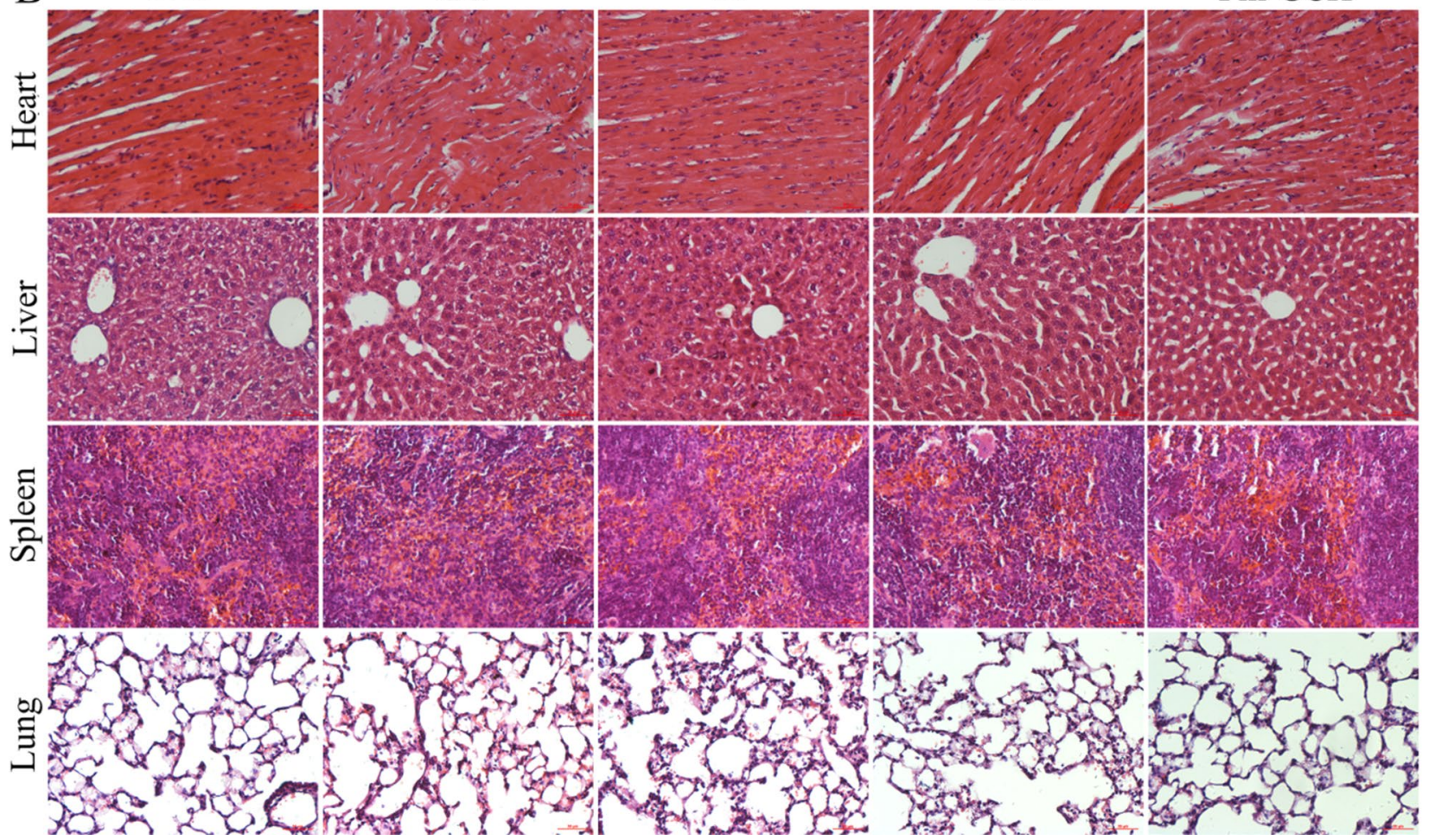

Fig. 10 A Hematological and hematobiochemical analysis of peripheral blood from the mice with SRNS administrated with PBS, GC, H, GCH and Pm-GCH. (a) RBC, (b) Hb, (c) WBC, (d) PLT, (e) ALT, (f) AST, (g) BUN and (h) CREA. B HE staining images of mice heart, liver, spleen and lung slices from different treatment groups at the 14 th day after different treatments

response. The application of this multifunctional targeted bionic sustained-release nanomedicine system can reduce the dose of glucocorticoids, improve glucocorticoid resistance and osteolysis, and enhance the therapeutic effect of nephrotic syndrome through the synergism of glycyrrhizin, glucocorticoids and platelet membrane vesicles.

\section{Acknowledgements}

Not applicable.

\section{Authors' contributions}

Conceived and designed the experiments: RG and QH. JL carried out the experiment. MZ and XX contributed to analyze the experimental results. JL wrote the manuscript. All authors read and approved the final manuscript.

\section{Funding}

This work was supported by Grants from the National Natural Science Foundation of China (82001165), the Wisdom Accumulation and Talent Cultivation Project of the Third xiangya hospital of Central South University (BJ202101), the Natural Science Foundation of Hunan Province (2021 JJ31002, 2021 JJ40926) and the Changsha Municipal Natural Science Foundation (kq2007056). 


\section{Availability of data and materials}

All data generated or analyzed during this study are included in this published article.

\section{Declarations}

\section{Ethics approval and consent to participate}

The authors obtained authorization to perform the tests on animal from the committee of Third Xiangya Hospital of Central South University.

\section{Consent for publication}

Not applicable.

\section{Competing interests}

The authors declare that they have no competing interests.

\section{Author details}

${ }^{1}$ Department of Blood Transfusion, The Third Xiangya Hospital, Central South University, Changsha 410013, China. ${ }^{2}$ Department of Pediatrics, The Third Xiangya Hospital, Central South University, Changsha 410013, China. ${ }^{3}$ School of Life Sciences, Central South University, Changsha 410013, China.

Received: 29 September 2021 Accepted: 26 November 2021

Published online: 13 December 2021

\section{References}

1. Agrawal S, Zaritsky JJ, Fornoni A, Smoyer WE. Dyslipidaemia in nephrotic syndrome: mechanisms and treatment. Nat Rev Nephrol. 2018;14(1):57-70.

2. Zhao F, Zhu J, Richman A, Fu Y, Huang W, Chen N, et al. Mutations in are implicated in steroid-resistant nephrotic syndrome. J Am Soc Nephrol. 2019;30(5):840-53.

3. Chotiyarnwong P, McCloskey E. Pathogenesis of glucocorticoidinduced osteoporosis and options for treatment. Nat Rev Endocrinol. 2020;16(8):437-47.

4. Sosa M, Gómez de Tejada M. Glucocorticoid-induced osteoporosis. N Engl J Med. 2019;380(14):1378-9.

5. Siji A, Karthik KN, Pardeshi VC, Hari PS, Vasudevan A. Targeted gene panel for genetic testing of south Indian children with steroid resistant nephrotic syndrome. BMC Med Genet. 2018;19(1):200.

6. Landini S, Mazzinghi B, Becherucci F, Allinovi M, Provenzano A, Palazzo $V$, et al. Reverse phenotyping after whole-exome sequencing in steroid-resistant nephrotic syndrome. Clin J Am Soc Nephrol. 2020:15(1):89-100.

7. Ghosh C, Hossain M, Solanki J, Najm IM, Marchi N, Janigro D. Overexpression of pregnane $X$ and glucocorticoid receptors and the regulation of cytochrome P450 in human epileptic brain endothelial cells. Epilepsia. 2017;58(4):576-85.

8. Brovkina A, Sychev D, Toropova O. Influence of CYP3A4, CYP3A5, and NR3C1 genes polymorphism on the effectiveness of glucocorticoid therapy in patients with endocrine ophthalmopathy. Vestn oftalmol. 2020;136:125-32.

9. Selyutina OY, Polyakov NE. Glycyrrhizic acid as a multifunctional drug carrier-from physicochemical properties to biomedical applications: a modern insight on the ancient drug. Int J Pharm. 2019;559:271-9.

10. Zhao Z, Xiao Y, Xu L, Liu Y, Jiang G, Wang W, et al. Glycyrrhizic acid nanoparticles as antiviral and anti-inflammatory agents for COVID-19 treatment. ACS Appl Mater Interfaces. 2021;13(18):20995-1006.

11. Qu L, Chen C, He W, Chen Y, Li Y, Wen Y, et al. Glycyrrhizic acid ameliorates LPS-induced acute lung injury by regulating autophagy through the PI3K/AKT/mTOR pathway. Am J Transl Res. 2019;11(4):2042-55.

12. Tucker I, Burley A, Petkova R, Hosking S, Penfold J, Thomas R, et al. Adsorption and self-assembly properties of the plant based biosurfactant, Glycyrrhizic acid. J Colloid Interface Sci. 2021;598:444-54.

13. Wang $Y$, Yang M, Ma Z, Liang Q, Tan H, Xiao C, Gao Y, et al. Effects of 18beta-glycyrrhizic acid and 18alpha-glycyrrhizic acid on mRNA and protein expression of cytochrome P450 3A in cultured rat primary hepatocyte. Zhongguo Zhong yao za zhi = Zhongguo zhongyao zazhi = China J Chin Mater Med. 2009;34(3):307-11.

14. Feng $Y$, Mei $L$, Wang $M$, Huang $Q$, Huang R. In vitroanti-inflammatory and pro-apoptotic effects of 18beta-glycyrrhetinic acid and models of rheumatoid arthritis. Front Pharmacol. 2021;12:681525.

15. Pavadai E, Kaur G, Wittlin S, Chibale K. Identification of steroid-like natu ral products as antiplasmodial agents by 2D and 3D similarity-based virtual screening. MedChemComm. 2017;8(6):1152-7.

16. Xie C, Li X, Wu J, Liang Z, Deng F, Xie W, et al. Anti-inflammatory activity of magnesium isoglycyrrhizinate through inhibition of phospholipase A2/arachidonic acid pathway. Inflammation. 2015;38(4):1639-48.

17. Cheng X, Qiu L, Wang F. 18a-Glycyrrhetinic acid (GA) ameliorates fructose-induced nephropathy in mice by suppressing oxidative stress, dyslipidemia and inflammation. Biomed Pharmacother. 2020;125:109702

18. Shelepova E, Kim A, Voloshin V, Medvedev N. Intermolecular voids in lipid bilayers in the presence of glycyrrhizic acid. J Phys Chem B. 2018;122(43):9938-46.

19. Selyutina O, Apanasenko I, Kim A, Shelepova E, Khalikov S, Polyakov N. Spectroscopic and molecular dynamics characterization of glycyrrhizin membrane-modifying activity. Colloids Surf, B Biointerfaces. 2016;147:459-66.

20. Yin Z, Zhu W, Wu Q, Zhang Q, Guo S, Liu T, et al. Glycyrrhizic acid suppresses osteoclast differentiation and postmenopausal osteoporosis by modulating the NF-KB, ERK, and JNK signaling pathways. Eur J Pharmacol. 2019;859:172550.

21. Gao S, Yang X, Xu J, Qiu N, Zhai G. Nanotechnology for boosting cancer immunotherapy and remodeling tumor microenvironment: the horizons in cancer treatment. ACS Nano. 2021:15:12567-603.

22. Song P, Fu H, Wang Y, Chen C, Ou P, Rashid R, et al. A microfluidic fieldeffect transistor biosensor with rolled-up indium nitride microtubes. Biosens Bioelectron. 2021;190:113264.

23. Kim B, Soepriatna A, Park W, Moon H, Cox A, Zhao J, et al. Rapid custom prototyping of soft poroelastic biosensor for simultaneous epicardial recording and imaging. Nat Commun. 2021;12(1):3710.

24. Li G, Sun B, LiY, Luo C, He Z, Sun J. Small-molecule prodrug nanoassemblies: an emerging nanoplatform for anticancer drug delivery. Small. 2021. https://doi.org/10.1002/smll.202101460.

25. Yang S, Huang C, Wang C, Shieh M, Chen K. The synergistic effect of hyperthermia and chemotherapy in magnetite nanomedicine-based lung cancer treatment. Int J Nanomed. 2020;15:10331-47.

26. Sun Y, Cao J, Wang X, Zhang C, Luo J, Zeng Y, et al. Hypoxia-adapted sono-chemodynamic treatment of orthotopic pancreatic carcinoma using copper metal-organic frameworks loaded with an ultrasound-induced free radical initiator. ACS Appl Mater Interfaces. 2021;13:38114-26

27. Peng H, Qin Y, Feng Y, He X, Li W, Zhang Y. Phosphate-degradable nanoparticles based on metal-organic frameworks for chemo-starvation-chemodynamic synergistic antitumor therapy. ACS Appl Mater Interfaces. 2021;13:37713-23.

28. Li P, Chen X, Shen Y, Li H, Zou Y, Yuan G, et al. Mucus penetration enhanced lipid polymer nanoparticles improve the eradication rate of Helicobacter pylori biofilm. J Control Release. 2019;300:52-63.

29. Jiang Y, Krishnan N, Zhou J, Chekuri S, Wei X, Kroll A, et al. Engineered cell-membrane-coated nanoparticles directly present tumor antigens to promote anticancer immunity. Adv Mater (Deerfield Beach, Fla). 2020:32(30):e2001808.

30. Wu P, Jiang X, Yin S, Yang Y, Liu T, Wang K. Biomimetic recombinant of red blood cell membranes for improved photothermal therapy. Nanobiotechnol. 2021;19(1):213.

31. Wei X, Gao J, Fang RH, Luk BT, Kroll AV, Dehaini D, et al. Nanoparticles camouflaged in platelet membrane coating as an antibody decoy for the treatment of immune thrombocytopenia. Biomaterials. 2016:111:116-23.

32. Li Y, Wu H, Jiang $X$, Zhang T, Zhou Y, Huang $L$, et al. Active stealth and self-positioning biomimetic vehicles achieved effective antitumor therapy. J Control Release. 2021;335:515-26.

33. Hu CM, Fang RH, Wang KC, Luk BT, Thamphiwatana S, Dehaini D, et al. Nanoparticle biointerfacing by platelet membrane cloaking. Nature. 2015:526(7571):118-21. 
34. Pitchford S, Cleary S, Arkless K, Amison R. Pharmacological strategies for targeting platelet activation in asthma. Curr Opin Pharmacol. 2019;46:55-64.

35. Wang Y, Zhu H, Tong J, Li Z. Ligustrazine improves blood circulation by suppressing Platelet activation in a rat model of allergic asthma. Environ Toxicol Pharmacol. 2016;45:334-9.

36. Wu C, Chen A, Yen G. Protective effects of glycyrrhizic acid and 18ß-glycyrrhetinic acid against cisplatin-induced nephrotoxicity in BALB/c mice. J Agric Food Chem. 2015;63(4):1200-9.

37. Hou S, Zheng F, Li Y, Gao L, Zhang J. The protective effect of glycyrrhizic acid on renal tubular epithelial cell injury induced by high glucose. Int J Mol Sci. 2014;15(9):15026-43.

38. Aguilar D, Strom J, Chen Q. Glucocorticoid induced leucine zipper inhibits apoptosis of cardiomyocytes by doxorubicin. Toxicol Appl Pharmacol. 2014;276(1):55-62.

39. Liang C, Wu J, Lai J, Ye S, Lin J, Ouyang H, et al. Protection effect of Zhen-Wu-Tang on adriamycin-induced nephrotic syndrome via inhibiting oxidative lesions and inflammation damage. Evid-Based Complement Altern Med. 2014;2014:131604.

40. Wei Y, Yan L, Luo L, Gui T, Jang B, Amirshaghaghi A, et al. Phospholipase A inhibitor-loaded micellar nanoparticles attenuate inflammation and mitigate osteoarthritis progression. Sci Adv. 2021;7(15):eabe6374.

41. Mortensen S, Jensen J, Andersen G. Solution structures of complement $C 2$ and its $C 4$ complexes propose pathway-specific mechanisms for control and activation of the complement proconvertases. J Biol Chem. 2016;291(32):16494-507.

42. Bai J, Xu J, Hang K, Kuang Z, Ying L, Zhou C, et al. Glycyrrhizic acid promotes osteogenic differentiation of human bone marrow stromal cells by activating the Wnt/ $\beta$-catenin signaling pathway. Front Pharmacol. 2021;12:607635.

43. Ramli E, Suhaimi F, Asri S, Ahmad F, Soelaiman I. Glycyrrhizic acid (GCA) as $11 \beta$-hydroxysteroid dehydrogenase inhibitor exerts protective effect against glucocorticoid-induced osteoporosis. J Bone Miner Metab. 2013;31(3):262-73.

\section{Publisher's Note}

Springer Nature remains neutral with regard to jurisdictional claims in published maps and institutional affiliations.

Ready to submit your research? Choose BMC and benefit from:

- fast, convenient online submission

- thorough peer review by experienced researchers in your field

- rapid publication on acceptance

- support for research data, including large and complex data types

- gold Open Access which fosters wider collaboration and increased citations

- maximum visibility for your research: over 100M website views per year

At BMC, research is always in progress.

Learn more biomedcentral.com/submissions 